\title{
AIP|
}

\section{Optical absorption spectra of palladium doped gold cluster cations}

Vladimir E. Kaydashev, Ewald Janssens, and Peter Lievens

Citation: The Journal of Chemical Physics 142, 034310 (2015); doi: 10.1063/1.4906072

View online: http://dx.doi.org/10.1063/1.4906072

View Table of Contents: http://scitation.aip.org/content/aip/journal/jcp/142/3?ver=pdfcov

Published by the AIP Publishing

\section{Articles you may be interested in}

Copper doping of small gold cluster cations: Influence on geometric and electronic structure

J. Chem. Phys. 135, 224305 (2011); 10.1063/1.3664307

Probing the structures of gas-phase rhodium cluster cations by far-infrared spectroscopy

J. Chem. Phys. 133, 214304 (2010); 10.1063/1.3509778

Photoabsorption spectra of small cationic xenon clusters from time-dependent density functional theory

J. Chem. Phys. 131, 214302 (2009); 10.1063/1.3265767

Weak metal-metal bonding in small manganese cluster ions, $\mathrm{Mn} \mathrm{N}+(\mathrm{N} 7$ )

J. Chem. Phys. 123, 174314 (2005); 10.1063/1.2062265

The interaction of gold clusters with methanol molecules: Infrared photodissociation of mass-selected Au n + $(\mathrm{CH} 3 \mathrm{OH}) \mathrm{m}$

J. Chem. Phys. 112, 752 (2000); 10.1063/1.480718

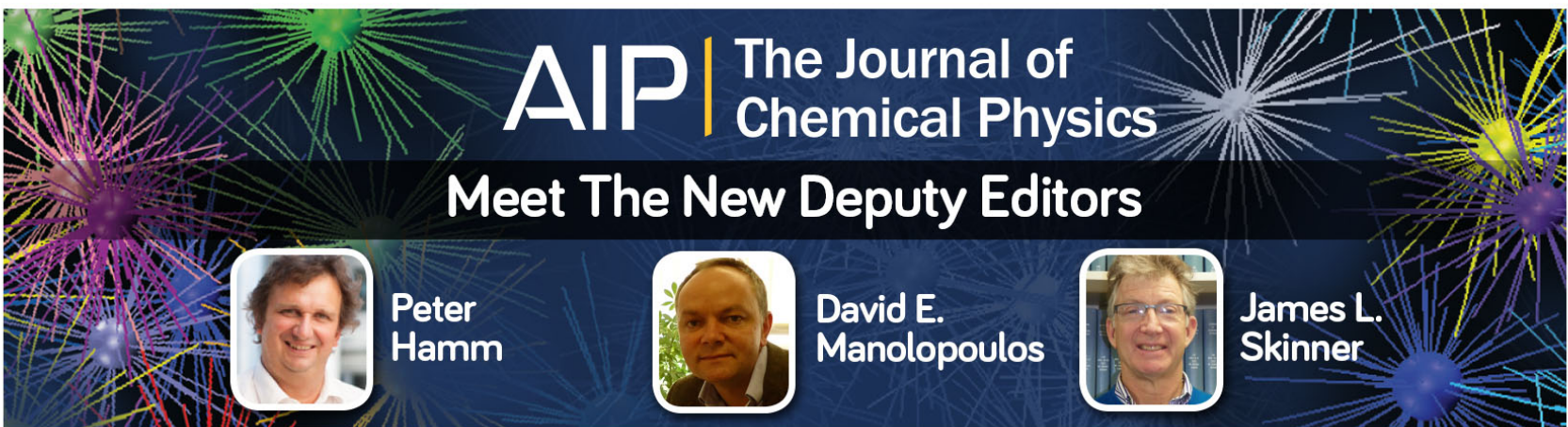




\title{
Optical absorption spectra of palladium doped gold cluster cations
}

\author{
Vladimir E. Kaydashev, Ewald Janssens, ${ }^{\text {a) }}$ and Peter Lievens \\ Laboratory of Solid State Physics and Magnetism, KU Leuven, Celestijnenlaan 200d-Box 2414, \\ B-3001 Leuven, Belgium
}

(Received 14 October 2014; accepted 5 January 2015; published online 21 January 2015)

\begin{abstract}
Photoabsorption spectra of gas phase $\mathrm{Au}_{n}{ }^{+}$and $\mathrm{Au}_{n-1} \mathrm{Pd}^{+}(13 \leq n \leq 20)$ clusters were measured using mass spectrometric recording of wavelength dependent Xe messenger atom photodetachment in the 1.9-3.4 eV photon energy range. Pure cationic gold clusters consisting of 15, 17, and 20 atoms have a higher integrated optical absorption cross section than the neighboring sizes. It is shown that the total optical absorption cross section increases with size and that palladium doping strongly reduces this cross section for all investigated sizes and in particular for $n=14-17$ and 20. The largest reduction of optical absorption upon Pd doping is observed for $n=15$. ( 2015 AIP Publishing LLC. [http://dx.doi.org/10.1063/1.4906072]
\end{abstract}

\section{INTRODUCTION}

It was recently shown that gold nanoparticles and atomic clusters have a high potential for applications in heterogeneous photocatalysis. ${ }^{1-5}$ Both optical properties and chemical reactivity play a crucial role in the design of novel environmental friendly applications, such as photocatalytic hydrogen generation $^{1,2}$ and $\mathrm{CO}$ oxidation. ${ }^{3}$ Other promising optical applications of gold nanoparticles and atomic clusters are optical antennas, ${ }^{6,7}$ bio- and chemosensors, ${ }^{8,9}$ extremely sensitive measurements using surface enhanced Raman scattering, ${ }^{10}$ high efficiency solar cells, ${ }^{11,12,6}$ photodiodes, ${ }^{7}$ and light emitting diodes. ${ }^{13}$ But the controlled modification of the optical absorption of gold nanoparticles and atomic clusters remains a challenge.

Large gold nanoparticles $(>5 \mathrm{~nm}$ ) show a broad plasmonic absorption band, whose position and shape do not drastically change by addition of a few atoms. Plasmonic particles have been extensively studied during the last decades and many of their properties are well established. ${ }^{14}$ Opposed to these larger particles, the optical absorption of small atomic clusters is extremely sensitive to the number and type of atoms in the cluster and is related to their size dependent electronic and geometric structure. ${ }^{15}$ The characterization of the optical absorption of pure and doped atomic gold clusters in the gas phase is difficult and only a small number of studies were undertaken so far. ${ }^{16-20}$ Due to a low number density of clusters in the gas phase, it is challenging to measure their optical absorption directly ${ }^{21}$ and action spectroscopy, monitoring light-induced changes in the clusters themselves, is usually used. A combination of wavelength dependent messenger atom photodetachment and mass spectrometry was used by Collings et al. to study small neutral and cationic $\mathrm{Au}_{n}$ clusters $\left(n=7,9,11\right.$, and 13). ${ }^{16}$ Optical absorption spectra were also recorded for other selected pure and doped gold clusters in different charge states: $\mathrm{Au}_{n}{ }^{+}(n=4$, 7-9), ${ }^{17,18} \mathrm{Au}_{n}{ }^{-}(n=7-11),{ }^{15} \mathrm{Au}_{4-m} \mathrm{Cu}_{m}{ }^{+}(m=0,1,2),{ }^{19}$ and $\mathrm{Au}_{4}{ }^{+} \cdot{ }^{20}$ In addition, experimental studies have been performed

\footnotetext{
a) Author to whom correspondence should be addressed. Electronic mail: ewald.janssens@fys.kuleuven.be.
}

on small Au clusters embedded in a rare gas matrix. ${ }^{22}$ The optical excitation spectra of larger gold clusters, in particular $\mathrm{Au}_{n}{ }^{ \pm, 0}(n=13-20)$, so far are not studied experimentally.

While size dependent optical properties of small gold clusters are not yet well studied, many experimental and theoretical efforts have been undertaken to characterize their geometric and ground state electronic properties. In particular, the electronic ground state of selected gold clusters was studied by photoelectron spectroscopy ${ }^{23,24}$ and geometric structures were determined by the analysis of vibrational spectra that are recorded using infrared radiation from a free electron lase ${ }^{24}$ and by electron diffraction measurements of trapped ions. ${ }^{25,26}$

The heavy gold atom is subject to large relativistic effects, ${ }^{27}$ causing a decrease of the effective Bohr radius of its valence $6 \mathrm{~s}$ electron. As a consequence, the valence sp band of $\mathrm{Au}$ is situated much closer to the valence $\mathrm{d}$ band as compared to $\mathrm{Ag}$ or $\mathrm{Cu}$. In particular, strong hybridization of the $5 \mathrm{~d}$ and $6 \mathrm{~s}$ orbitals in gold favors unusually large planar clusters $\left(n \leq 12\right.$ for anions ${ }^{26}$ and $n<7$ for cations ${ }^{28}$ ) and interesting 3D structures, such as cage-like structures that are capable to accommodate a guest atom for $\mathrm{Au}_{n}{ }^{-}(n=16-18)^{25,26,29}$ and stable tetrahedral $\mathrm{Au}_{20}{ }^{ \pm, 0}$ structures. ${ }^{24,30,31}$

Doping of gold clusters allows to modify their optical and chemical properties. ${ }^{32-35}$ Adding a single atom or a single electron can dramatically change the cluster's geometric and electronic structure. Indeed, photofragmentation studies probing the size-dependent stability of Au clusters doped with a single (transition) metal atom revealed significant dopantinduced changes of the cluster electronic structure. ${ }^{36-39}$ The altered electronic and geometric structure also modifies the cluster's stability and chemical reactivity. ${ }^{4,34,40}$

Both optical absorption and chemical properties are important for purposes of photocatalysis. Since both depend on the geometric and electronic structure, changes in the optical absorption and the chemical properties are correlated. A study of the size and composition dependence of the optical properties thus can provide relevant information to tune the reactivity of clusters. The effect of alloying on the optical properties was studied theoretically for $\mathrm{AgAu}$ nanoclusters ${ }^{41,42}$ and 
experimentally for AuPd nanocrystals. ${ }^{43-45}$ Palladium doping may change the chemical properties of gold particles, related to a dopant induced observed shift of the electronic energy levels. Pd doping of gold clusters can also trigger the formation of endohedral caged structures as was recently shown for $\mathrm{Au}_{24} \mathrm{Pd} .{ }^{46}$ It is remarkable that $\mathrm{Ag}$ and $\mathrm{Pd}$ dopings induce opposite effects on the optical ${ }^{43,47}$ and chemical ${ }^{48-50}$ properties of the clusters. On one hand, it was theoretically predicted that a Pd dopant induced change of the electronic structure enhances the chemical reactivity of gold clusters towards $\mathrm{CO}$ and $\mathrm{O}_{2}$ in $\mathrm{Au}_{n} \mathrm{Pd}(n \leq 7) .{ }^{51}$ On the other hand, a decreased $\mathrm{CO}$ adsorption probability was found experimentally in Ag doped gold clusters, $\mathrm{Au}_{n} \mathrm{Ag}$ with $n \leq 45 .{ }^{52}$ The interaction between $\mathrm{Au}$ and $\mathrm{Pd}$ modifies the s-d and d-d bonding in the clusters, in particular via $\mathrm{Au}(6 \mathrm{~s})-\mathrm{Pd}(4 \mathrm{~d})$ and $\mathrm{Au}(5 \mathrm{~d})-\mathrm{Pd}(4 \mathrm{~d})$ hybridization. ${ }^{53}$ The dopant induced charge redistribution unavoidably influences the optical and chemical properties of the gold clusters. ${ }^{46}$

In the present work, we use action spectroscopy with adsorbed Xe messenger atoms to investigate the electronic excitation spectra of cationic pure gold clusters and gold clusters doped with one palladium atom for sizes ranging from 13 to 20 atoms. The optical absorption spectra are measured in the gas phase by photodissociation of the corresponding cluster-Xe complexes in the photon energy range of 1.9-3.4 eV.

\section{EXPERIMENTAL METHODS}

$\mathrm{Au}_{n}{ }^{+}$and $\mathrm{Au}_{n-1} \mathrm{Pd}^{+}$clusters are produced simultaneously in a dual-target dual-laser vaporization source. ${ }^{54}$ The amount of ablated material is controlled by two independent pulsed $\mathrm{Nd}$ :YAG lasers operating in the second harmonic $(532 \mathrm{~nm}$, $10 \mathrm{~Hz}$ ) with pulse energies of about $22 \mathrm{~mJ}$ and $25 \mathrm{~mJ}$ for the $\mathrm{Au}$ (ACI Alloy, 99.98\% purity) and Pd (ACI Alloy, 99.95\% purity) targets, respectively. He gas is introduced by a pulsed supersonic valve just before laser ablation, cools the metal vapor, and initializes the clustering process. The clusters are thermalized by heat exchange via the carrier gas with walls of the source, which is cooled by a continuous flow of liquid nitrogen. A temperature controller allows stabilizing any source temperature in the $80-320 \mathrm{~K}$ range. By addition of a small fraction of $\mathrm{Xe}(5 \%)$ to the He carrier gas, cluster-Xe complexes are formed. The central part of the cluster beam is selected by a conical skimmer and enters the extraction region where cationic clusters are accelerated into a reflectron time-of-flight mass spectrometer.

To perform the photodissociation experiments, the clusterXe complexes are excited by tunable laser light from a QuantaRay Nd:YAG pumped BBO-based optical parametric oscillator (OPO). The OPO (MOPO-710) is equipped with a frequency doubling option and is operated at $10 \mathrm{~Hz}$ with a pulse length of $8 \mathrm{~ns}$ and a bandwidth of $4-20 \mathrm{~cm}^{-1}$. The laser beam diameter $(1 \mathrm{~cm})$ was optimized to have a maximal spatial overlap with the molecular cluster beam. The energy per pulse used for photodetachment is monitored by a pyroelectric energy sensor (ThorLabs, ES111C) and maintained below $6 \mathrm{~mJ}$ to avoid two-photon processes. ${ }^{15}$ The laser beam is chopped by a homebuild chopper that is synchronized with the OPO and operating at $5 \mathrm{~Hz}$. This allows to alternately record mass spectra with and without photoexcitation of the clusters, each of which is averaged over 5000 cycles in different channels of the oscilloscope (Tektronix TDS5052). The reference spectra without photoexcitation are used to normalize for cluster production fluctuations. In the one-photon absorption regime, the absorption of a single photon leads to photodetachment of the Xe messenger atom. The photodepletion, $I / I_{0}$, with $I$ and $I_{0}$ the abundance of a specific cluster with and without photoexcitation, respectively, is measured as function of the photon energy. $I / I_{0}$ can be converted into the absorption cross section $\sigma$ using the modified Lambert-Beer-Law, ${ }^{15}$

$$
\frac{I}{I_{0}}=1-b+b \exp (-\sigma \Phi)
$$

where $\Phi$ is the photon fluence. The overlap factor $b$ takes into account the imperfect spatial and temporal overlap between the dissociation laser and the extracted clusters. In the present experiment, the overlap factor is estimated to be 0.85 .

To avoid overlap of peaks in the mass range of interest, the source conditions were optimized such that the amount of $\mathrm{Pd}$ doping in the clusters and the number of adsorbed $\mathrm{Xe}$ atoms are fairly small. For instance, lowering the source temperature stimulates formation of complexes with multiple $\mathrm{Xe}$ atoms, $\mathrm{Au}_{n}{ }^{+} \cdot \mathrm{Xe}_{m}$ and $\mathrm{Au}_{n-1} \mathrm{Pd}^{+} \cdot \mathrm{Xe}_{m}$ with $m>2$, resulting in overlapping peaks in the mass spectra. In addition, laser powers and the time sequence of the cluster production were optimized to avoid the production of $\mathrm{Au}_{n} \mathrm{Pd}_{k}{ }^{+}$with $k>2$.

\section{RESULTS AND DISCUSSION}

\section{A. Cluster-rare gas complex formation}

Rare gases are expected to form van der Waals complexes with metal clusters. For gold clusters, the cluster-rare gas binding energy was found to be about $0.20-0.25 \mathrm{eV}$ for $\mathrm{Ar}^{19}$ and is expected to be somewhat larger for Xe. While $\mathrm{Au}_{n}{ }^{+} \cdot \mathrm{Ar}_{m}$ clusters can be easily obtained for very small clusters $(n<14)$, the production of larger cluster-Ar complexes becomes problematic. Since heavier rare gas atoms are more polarizable, they form stronger bonds with metal clusters. Therefore, Xe was used as messenger atom for probing the optical absorption of the species discussed here.

Under the experimental conditions described above and at a source temperature of $260 \mathrm{~K}, \mathrm{Au}_{n}{ }^{+}$and $\mathrm{Au}_{n-1} \mathrm{Pd}^{+}$clusters and their $\mathrm{Xe}$ complexes, $\mathrm{Au}_{n}{ }^{+} \cdot \mathrm{Xe}_{m}$ and $\mathrm{Au}_{n-1} \mathrm{Pd}^{+} \cdot \mathrm{Xe}_{m}$, are readily formed for $n \leq 19$ and $n \leq 20$, respectively.

The likelihood of rare gas attachment on clusters can provide structural information. In particular, size-dependent changes of the clusters' ability to form van der Waals complexes have been related to $2 \mathrm{D} \rightarrow 3 \mathrm{D}$ structural transitions. ${ }^{15}$ They are associated with a drop in the cluster polarizability due to a decrease of the volume per atom in more compact structures. ${ }^{55}$ Other geometrical factors responsible for changes in the formation of rare gas complexes were attributed to the presence of planar faces ${ }^{56}$ and endohedral doping. ${ }^{57}$

Previous studies of $\mathrm{Au}_{n}{ }^{+}$and $\mathrm{Au}_{n-1} \mathrm{Cu}^{+}$at $T<203 \mathrm{~K}$ showed a drop in the likelihood of Ar attachment after $n=7$ together with local enhancements at $n=10,11$, and $15{ }^{19} \mathrm{In}$ the present study, the same trend for $\mathrm{Ar}$ attachment to $\mathrm{Au}_{n}{ }^{+}$ 
was observed (see Fig. S1 in the supplementary material). ${ }^{58}$ The likelihood of rare gas attachment can be quantized by $F_{n}$,

$$
F_{n}=\sum_{m=1}^{2} I_{n m} / \sum_{m=0}^{2} I_{n m}
$$

where $I_{n m}$ is the abundance of $\mathrm{Au}_{n}{ }^{+} \cdot \mathrm{Xe}_{m}$ for the pure gold and of $\mathrm{Au}_{n-1} \mathrm{Pd}^{+} \cdot \mathrm{Xe}_{m}$ for the palladium doped gold clusters. $F_{n}$, deduced by averaging ten mass spectra measured under the same conditions, is presented in Fig. 1. The error bars reflect the standard deviation on the mean.

The $\mathrm{Au}_{n}{ }^{+}$and $\mathrm{Au}_{n-1} \mathrm{Pd}^{+}$clusters readily attach Xe for $n \leq 19$ and $n \leq 20$, respectively, and $F_{n}$ decreases strongly for larger sizes. We speculate that the drop of $F_{n}$ for $\mathrm{Au}_{n}{ }^{+}$at $n>19$ is associated with the drop of the static polarizability per atom caused by evolution of the clusters to more compact 3D structures, similar to the polarizability drop that is observed for the 2D-3D transition at smaller sizes. ${ }^{55}$ Indeed, computations predict that neutral, cationic, and anionic $\mathrm{Au}_{20}$ clusters all have a compact tetrahedral symmetry with only slightly changed interatomic distances. ${ }^{31,59}$

Size dependent alterations in $F_{n}$ might be associated with face planarity of clusters' 3D structures. ${ }^{56}$ The interaction potential of the rare gas atom with $3 \mathrm{D}$ structures and with the flat surfaces drops as $\sim R^{-6}$ and $\sim R^{-3}$, respectively. For instance, a significantly higher Xe and Ar attachment ability of anionic $\mathrm{Au}_{20}{ }^{-}$with respect to neighboring sizes was observed earlier ${ }^{15,56}$ and was attributed to the higher planarity of its faces. ${ }^{56}$ The slightly Jahn-Teller distorted $D_{2 d}$ tetrahedral structure of the anionic $\mathrm{Au}_{20}{ }^{-}$and the co-existence of distorted icosahedral and tetrahedral structural motifs for $\mathrm{Au}_{20}{ }^{+}$were proposed based on trapped ion electron diffraction experiments. ${ }^{59}$ Opposed to the anionic $\mathrm{Au}_{20}{ }^{-}$, the cationic $\mathrm{Au}_{20}{ }^{+}$does not show a local increase in the likelihood of Xe attachment. A lower polarizability of the $\mathrm{Au}_{20}{ }^{+}$cation is in line with the idea of co-existence of two isomers, with the icosahedral one having a lower face planarity than the ground state tetrahedral isomer.

$\mathrm{Pd}$ doping can modify the geometry of the $\mathrm{Au}_{20}{ }^{+}$cluster and, that way, also the polarizability, which is reflected by $F_{n}$. The Pd dopant induced shift of the largest size for which

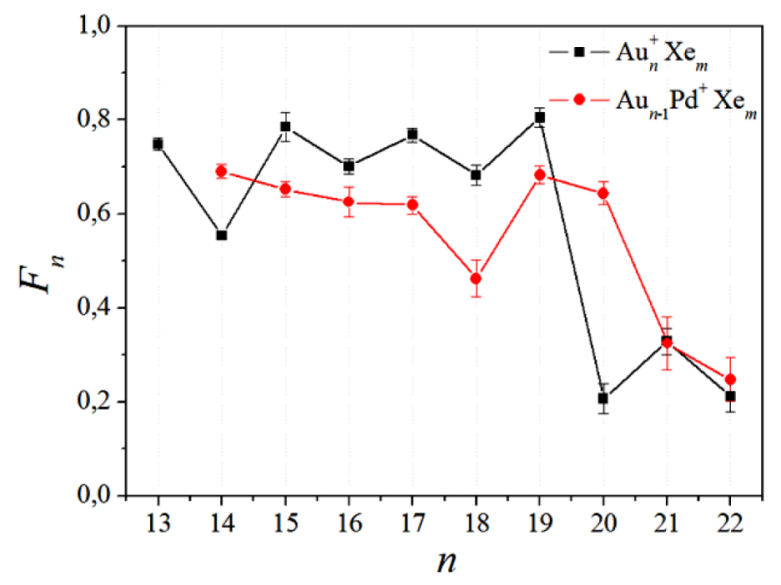

FIG. 1. Fraction of rare gas complexes, $F_{n}$, characterizing the size-dependent changes in Xe complex formation efficiency of $\mathrm{Au}_{n}{ }^{+}$and $\mathrm{Au}_{n-1} \mathrm{Pd}^{+}(13 \leq n$ $\leq 22$ ). The data were obtained using a $\mathrm{He}-\mathrm{Xe}(5 \%), p=8$ bars, $T=263 \mathrm{~K}$ carrier gas mixture. there is a significant amount of $\mathrm{Xe}$ attachment (from $\mathrm{Au}_{19}{ }^{+}$to $\mathrm{Au}_{19} \mathrm{Pd}^{+}$) points to an increase of the static polarizability of $\mathrm{Au}_{20}{ }^{+}$upon replacement of a single $\mathrm{Au}$ atom by a $\mathrm{Pd}$ atom.

\section{B. Optical absorption spectra of $\mathrm{Au}_{\mathrm{n}}{ }^{+} \cdot \mathrm{Xe}$}

Photodepletion spectra of $\mathrm{Au}_{n}{ }^{+} \cdot \mathrm{Xe}(n=13-20)$ complexes are measured in the $1.9-3.4 \mathrm{eV}$ range. The applied laser fluence was maintained at $2-8 \mathrm{~mJ} / \mathrm{cm}^{2}$ to obtain a significant depletion but low enough so that multiphoton cluster fragmentation or photo-ionization is avoided. Following single photon absorption, one or more $\mathrm{Xe}$ atoms can be detached from the cluster-Xe complexes, basically allowing for two reaction pathways

$$
\begin{gathered}
\mathrm{Au}_{n}^{+} \cdot \mathrm{Xe}_{m} \rightarrow \mathrm{Au}_{n}^{+}+m \mathrm{Xe}, \\
\mathrm{Au}_{n}^{+} \cdot \mathrm{Xe}_{m} \rightarrow \mathrm{Au}_{n}^{+} \cdot \mathrm{Xe}_{m-1}+\mathrm{Xe} .
\end{gathered}
$$

The cluster-Xe bond strength is expected to be at maximum $0.5 \mathrm{eV} .^{15,19,24}$ In the investigated photon energy range, the energy of a single photon is thus high enough to break the $m$ Xe-cluster bonds ( $m=1$ or 2), favoring reaction (3). This assumption is supported by the observation that the depletion spectra obtained for $\mathrm{Au}_{n}{ }^{+} \cdot \mathrm{Xe}$ and $\mathrm{Au}_{n}{ }^{+} \cdot \mathrm{Xe}_{2}$ show absorption bands of comparable intensities and at similar energies, though slightly blue shifted for $\mathrm{Au}_{n}{ }^{+} \cdot \mathrm{Xe}_{2}$ (see Fig. S2 of the supplementary material). ${ }^{58}$ Systematic blue shifts of the bands of multiple rare gas tagged clusters, in comparison to bands of pure and singly rare gas tagged species, have been observed earlier for small argon tagged cationic gold clusters. ${ }^{17,18}$ Should reaction (4) be preferred, the depletion of $\mathrm{Au}_{n}{ }^{+} \cdot \mathrm{Xe}_{2}$ would be reflected by an increase of the $\mathrm{Au}_{n}{ }^{+} \cdot \mathrm{Xe}$ signal upon photoexcitation, which was not observed. However, the occurrence of reaction (4) cannot be fully excluded, since the above argument only holds if the $\mathrm{Au}_{n}{ }^{+} \cdot \mathrm{Xe}$ and $\mathrm{Au}_{n}{ }^{+} \cdot \mathrm{Xe}_{2}$ complexes have absorption bands at different energies. In case reaction (4) takes place, the measured absorption cross sections of $\mathrm{Au}_{n}^{+} \cdot \mathrm{Xe}$ are systematically underestimated (the observed depletion is less because of fragmentation of $\mathrm{Au}_{n}{ }^{+} \cdot \mathrm{Xe}_{2}$ into $\left.\mathrm{Au}_{n}{ }^{+} \cdot \mathrm{Xe}\right)$. The slightly lower cross sections obtained for $\mathrm{Au}_{n}{ }^{+} \cdot \mathrm{Xe}$ as compared to $\mathrm{Au}_{n}{ }^{+} \cdot \mathrm{Xe}_{2}$ (Fig. S2) indicate that reaction (4) may occur in addition to (3). Given the overall similarity of both spectra and given the higher signal-to-noise ratio for the single Xe-tagged species, we concentrate below on the depletion spectra of $\mathrm{Au}_{n}{ }^{+}$.Xe with the remark that the cross sections may be slightly underestimated if there is a sizeable fraction of $\mathrm{Au}_{n}{ }^{+} \cdot \mathrm{Xe}_{2}$ complexes in the molecular beam.

The wavelength dependent absorption cross sections of $\mathrm{Au}_{n}{ }^{+}(n=13-20)$ are obtained using Eq. (1) and presented in the left column of Fig. 2. To allow quantifying the size evolution and the influence of the dopant atom, the absorption spectra were approximated by a sum of $N$ Gaussians, representing $N$ optical excitations (or groups of excitations that are close in energy)

$$
\sigma(\hbar \omega)=\sum_{i=1}^{N} f_{i} \cdot G_{E_{i}, F W H M_{i}}(\hbar \omega),
$$

where $G_{E_{i}, F W H M_{i}}(\hbar \omega)$ are normalized Gaussian functions with mean $E_{i}$, full width half maximum $F W H M_{i}$, and oscillator 


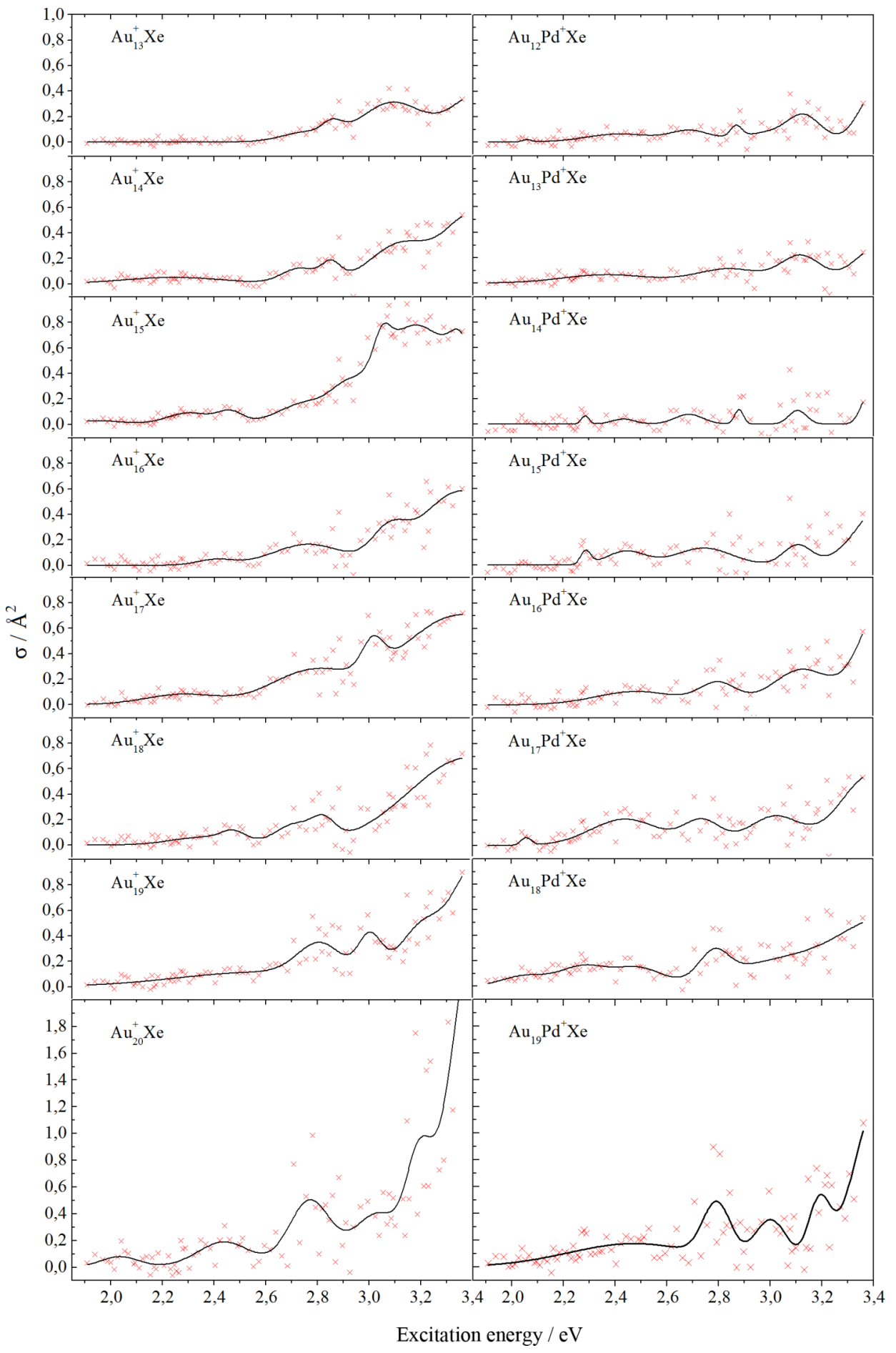

FIG. 2. Optical absorption spectra of bare and palladium doped gold cluster cations, $\mathrm{Au}_{n}{ }^{+}$and $\mathrm{Au}_{n-1} \mathrm{Pd}^{+}(13 \leq n$ $\leq 20)$. The experimental data points are shown by red crosses. Solid curves represents fits of averages (over 5 adjacent points) of the experimental data by multiple Gaussian functions using Eq. (5). strength $f_{i}$ of the respective optical excitation. All the Gaussians were imposed to have a $F W H M$ larger than $0.04 \mathrm{eV}$ (at least five data points). The $\sigma(\hbar \omega)$ curve was fit to the experimental data after performing a five adjacent data points averaging. The number of Gaussians used for the fitting procedure is the smallest number $N$ that yielded a fair fit of the absorption spectra. Evidently, there is some arbitrariness in the analysis procedure. Therefore, we also have evaluated integrated areas under the absorption spectra. The size and dopant dependence of the absorption spectra of $\mathrm{Au}_{n}{ }^{+}$was quantified by dividing the investigated energy range $(1.9-3.38 \mathrm{eV})$ into five intervals. Integrated areas under the fitted absorption curves were calcu- lated in these intervals and are shown in Fig. 3(a). The size evolution of the total absorption in the energy range 1.9-3.38 $\mathrm{eV}$ is shown in Fig. 3(c).

The pure $\mathrm{Au}_{n}{ }^{+}$clusters show broad overlapping absorption bands in the $2.55-3.38 \mathrm{eV}$ part of the spectrum, while the absorption intensity in the 1.9-2.55 eV range is lower showing only a few weak bands. The considered clusters may have several energetically close lying isomers. ${ }^{26}$ Thus, the broad bands in the absorption spectra could stem from a single isomer with many transitions at close-lying energies and/or could originate from different isomers in the cluster beam. Idrobo et al. ${ }^{60}$ theoretically predicted many optical transitions for neutral $\mathrm{Au}_{n}$ 


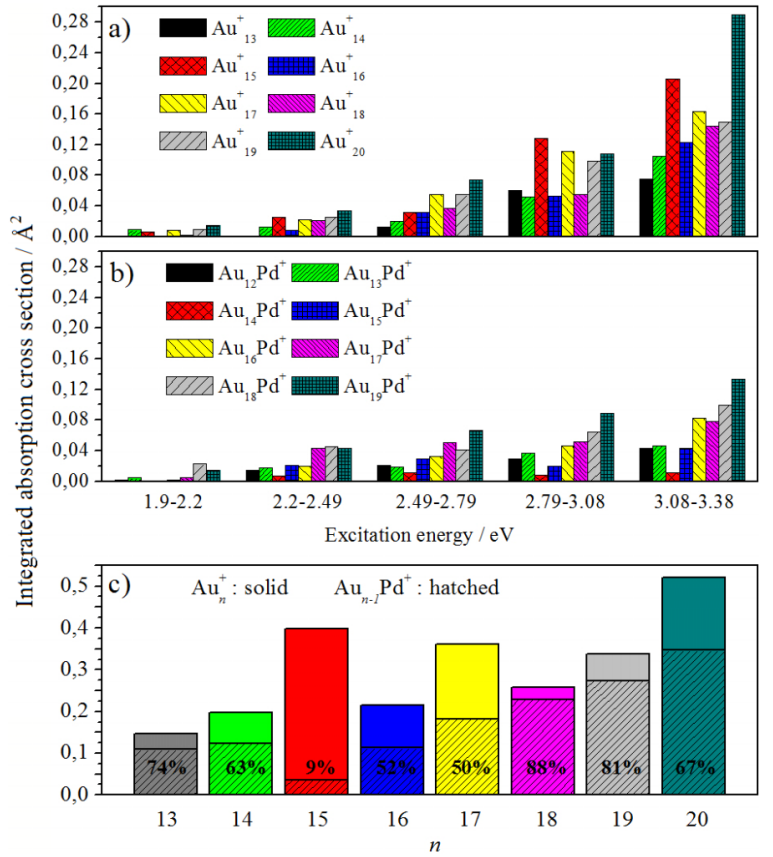

FIG. 3. Integrated absorption cross sections for $\mathrm{Au}_{n}{ }^{+}$(a) and $\mathrm{Au}_{n-1} \mathrm{Pd}^{+}$ (13 $\leq n \leq 20$ ) (b) clusters for five intervals of the investigated 1.9-3.4 eV photon energy range and total integrated absorption cross section in the 1.9-3.4 eV range (c). Solid and hatched bars in (c) represent pure $\mathrm{Au}_{n}{ }^{+}$and doped $\mathrm{Au}_{n-1} \mathrm{Pd}^{+}$clusters, respectively.

( $n=13,14$, and 20) in the higher energy part of the absorption spectra and few in the lower energy part. Despite the possible presence of isomers in the experiment and the different charge state, the experimental results for $\mathrm{Au}_{13}{ }^{+}$and $\mathrm{Au}_{20}{ }^{+}$are in qualitative agreement with these theoretical predictions ${ }^{60}$ for the calculated ground states of $\mathrm{Au}_{13}$ and $\mathrm{Au}_{20}$ (see supplementary material) ${ }^{58}$ The major features of the absorption spectra are described below for each cluster size.

$\mathbf{A u}_{13}{ }^{+}$does not show any measurable optical absorption transitions in the investigated energy region below $2.55 \mathrm{eV}$. A fit of the experimental curve by a sum of Gaussians gives optical absorption bands at about 2.75, 2.86, 3.09, and $3.4 \mathrm{eV}$. The spectrum of $\mathbf{A u}_{\mathbf{1 4}}{ }^{+}$shows one smooth and broad band with local maxima around $2.73,2.85,3.13$, and $3.4 \mathrm{eV}$. The latter value has some arbitrariness in assignment since this is the maximum of the measurement range. In addition, a low intensity broad band centered at $2.24 \mathrm{eV}$ appears in the low energy region. $\mathbf{A u}_{15}{ }^{+}$reveals the second highest absorption cross section among the investigated sizes in the energy range of 3.08-3.38 eV and an extended band of absorption increasing from 2.6 to $3.0 \mathrm{eV}$. In addition, $\mathrm{Au}_{15}{ }^{+}$has two absorption bands between $2.20 \mathrm{eV}$ and $2.55 \mathrm{eV}$. The experimental absorption spectrum of $\mathbf{A u}_{16}{ }^{+}$has a broad band with maxima at 2.76, 3.07, and $3.35 \mathrm{eV}$ and a low intensity band between 2.3 and $2.5 \mathrm{eV}$. $\mathbf{A u}_{17}{ }^{+}$has broad absorption features near 2.76, 3.0, and $3.4 \mathrm{eV}$. The band at $3.0 \mathrm{eV}$, that is also seen for other sizes, is much more pronounced for this size. The optical absorption spectrum of $\mathrm{Au}_{17}{ }^{+}$also shows low intensity transitions in the low energy region with one broad band centered at $2.27 \mathrm{eV}$.

The optical absorption spectra of $\mathbf{A u}_{n}{ }^{+}(\boldsymbol{n}=\mathbf{1 8 - 2 0})$ show a lot of similarities. Several intense absorption bands are observed between 2.6 and $3.38 \mathrm{eV}$. Bands near 2.8 and 3.4
$\mathrm{eV}$ are observed for all three sizes, be it with slightly shifted positions. $\mathrm{Au}_{19}{ }^{+}$and $\mathrm{Au}_{20}{ }^{+}$in addition have a band at $3.0 \mathrm{eV}$, which is absent for $\mathrm{Au}_{18}{ }^{+}$. For $\mathrm{Au}_{19}{ }^{+}$, the absorption cross section increases monotonically from 1.9 to $2.6 \mathrm{eV}$, while a band near $2.45 \mathrm{eV}$ with low intensity can be detected for both $\mathrm{Au}_{18}{ }^{+}$and $\mathrm{Au}_{20}{ }^{+}$. The integrated absorption cross section of $\mathrm{Au}_{20}{ }^{+}$in the $2.94-3.38 \mathrm{eV}$ range is significantly enhanced compared to all other sizes studied in the present work.

Only a few experimental ${ }^{16}$ and theoretical ${ }^{60}$ studies on gold clusters in the size range of 13-20 atoms are available in the literature. Our experimental results are in qualitative agreement with action spectroscopy measurements by Collings et al. for $\mathrm{Au}_{13}{ }^{0,+}$ clusters ${ }^{16}$ and with calculated optical excitation spectrum for $\mathrm{Au}_{13} \cdot{ }^{60} \mathrm{~A}$ theoretical analysis of the optical excitations of neutral $\mathrm{Au}_{20}$ showed transitions in the energy range below $3 \mathrm{eV}$ that were claimed to correspond to excitations of face-centered and edge atoms of the tetrahedral structure, while the excitations in the $3-4 \mathrm{eV}$ range mainly originate from vertex atoms. ${ }^{60}$ The tetrahedral geometry has been confirmed experimentally for $\mathrm{Au}_{20}$ and also $\mathrm{Au}_{19}$ was shown to have a tetrahedral geometry but with one missing vertex atom. ${ }^{24}$ If the absorption bands around 3-4 eV indeed originate from electronic excitations of vertex atoms, the growth of the oscillator strength in the $n=18-20$ size range can be explained by a tetrahedral geometry for those three sizes with one and two missing vertex atoms in $\mathrm{Au}_{19}{ }^{+}$and $\mathrm{Au}_{18}{ }^{+}$, respectively.

The size evolution of the optical absorption in different energy ranges between 1.9 and $3.38 \mathrm{eV}$ is readily quantified using the histograms presented in Fig. 3(a). The integrated optical absorption over the entire studied photon energy range is plotted in Fig. 3(c). An overall increase of the integrated absorption cross section is observed with increasing cluster size (Figs. 2 and 3(c)), with the largest value found for $\mathrm{Au}_{20}{ }^{+}$. The increase of the integrated absorption cross section with size is non-monotonic, clusters consisting of $15,17,19$, and 20 atoms demonstrate enhanced cross sections compared to neighboring sizes. Their total absorption cross sections are, respectively, 2.7, 2.4, 2.3, and 3.5 times higher than the one of $\mathrm{Au}_{13}{ }^{+}$. The overall increase of the cross section with size might be related to an increase of the static polarizability with the number of atoms as was found theoretically for neutral $\mathrm{Au}_{n}$ ( $n=2-13,20)$ clusters. ${ }^{60}$ In addition, even-odd oscillations in polarizabilities with cluster size, that were attributed to electron sub-shell closing, ${ }^{60}$ likely explain the local maxima in the absorption cross section for $\mathrm{Au}_{n}{ }^{+}$with $n=15,17$, and 19. Finally, the enhanced absorption cross section for $\mathrm{Au}_{20}{ }^{+}$is likely related to its tetrahedral symmetry.

\section{Influence of Pd doping on absorption spectra of the cationic gold clusters}

Photodepletion spectra of palladium doped $\mathrm{Au}_{n-1} \mathrm{Pd}^{+} \cdot \mathrm{Xe}$ ( $n=13-20)$ complexes are measured and analysed using the same approach as for the pure gold clusters. Their wavelength dependent absorption cross sections are shown in the right column of Fig. 2 and the integrated absorption cross sections for five equivalent spectral ranges in Fig. 3(b). Similar to pure cationic gold clusters, the integrated absorption cross section in the visible range grows with increasing cluster size (Fig. 3(c)). 
More strikingly, for all studied sizes, the total absorption cross section is significantly reduced upon substitution of a single $\mathrm{Au}$ atom by a single Pd atom. Comparing the effect of Pd doping in the different spectral ranges (Figs. 3(a) versus 3(b)), one can notice that besides a large decrease of the absorption cross section in the high energy spectral ranges, some sizes show an increase of the absorption cross section in the low energy part of the spectrum. These effects are described in more detail below.

$\mathrm{Au}_{12} \mathbf{P d}^{+}$: The main effect of substituting one $\mathrm{Au}$ atom by $\mathrm{Pd}$ on the optical absorption spectrum of $\mathrm{Au}_{13}{ }^{+}$is a decrease of the intense band near $3.09 \mathrm{eV}$. The absorption band around $2.75 \mathrm{eV}$ apparently shifts by $0.07 \mathrm{eV}$ to the red and the absorption near $2.85 \mathrm{eV}$ becomes narrower. $\mathrm{Au}_{12} \mathrm{Pd}^{+}$also has some weak transitions in the low energy region $(<2.5 \mathrm{eV})$, where there is hardly any absorption for $\mathrm{Au}_{13}{ }^{+}$. The appearance of low energy transitions in the absorption spectra of Pd doped clusters may point to a lower HOMO-LUMO gap that can be bridged by lower energy photons. Most likely, the empty Pd 4d and particularly, the low-energy Pd 5s orbitals are involved in these low energy excitations.

In the low energy range $(1.9-2.79 \mathrm{eV})$, the absorption cross section of $\mathbf{A u}_{13} \mathbf{P d}^{+}$does not significantly change in comparison with $\mathrm{Au}_{14}{ }^{+}$. In the higher energy part of the spectrum $(2.79-3.38 \mathrm{eV})$, there are however significant changes. The integrated absorption cross section of the broad optical absorption band of $\mathrm{Au}_{14}{ }^{+}$with local maxima at 3.13 and $3.4 \mathrm{eV}$ is reduced by $47 \%$ upon Pd doping (Fig. 3(b)). The absorption in the entire measured range is reduced by $37 \%$ (Fig. 3(c)).

The largest reduction of optical absorption cross section among the considered species is observed for $\mathbf{A u}_{14} \mathbf{P d}^{+}$, $\mathbf{A u}_{15} \mathbf{P d}^{+}$, and $\mathbf{A u}_{16} \mathbf{P d}^{+}$. With respect to bare gold clusters with the same number of atoms, the total area under the absorption curve in the $1.9-3.38 \mathrm{eV}$ range is reduced by $91 \%, 48 \%$, and $50 \%$, respectively (Fig. 3(c)). The observed drastic changes of optical absorption spectra may be related to important dopant induced structural changes such as the formation of endohedral caged structures in which the Pd atoms are highly coordinated by surrounding gold atoms. The possibility for such Pd dopant induced formation of an endohedral caged structure was recently demonstrated for $\mathrm{Au}_{24} \mathrm{Pd} .{ }^{46}$ Endohedral doping may possibly also take place in smaller clusters because $\mathrm{Au}_{16}{ }^{-}$is a hollow spherical cage, large enough to accommodate a dopant atom..$^{61,62}$ As a result of endohedral doping, the number of $\mathrm{Au}-\mathrm{Pd}$ bonds, and thus the influence of the $\mathrm{Pd}$ dopant on the electronic structure of the cluster, is maximized. In case of $\mathbf{A u}_{\mathbf{1 4}} \mathbf{P d}^{+}$, doping induces a systematic decrease of the absorption spectrum, both in the lower and the higher energy range. Because of the low intensity of the remaining bands, their precise characterization is limited. The absorption spectrum of $\mathbf{A u}_{15} \mathbf{P d}^{+}$in the higher energy range (2.5-3.38 eV) shows, with respect to $\mathrm{Au}_{16}{ }^{+}$, a strong reduction of the three main broad bands at 2.76, 3.07, and $3.4 \mathrm{eV}$ without considerable shift of their position. However, the total absorption cross section of the weaker absorption bands of $\mathrm{Au}_{15} \mathrm{Pd}^{+}$in the lower energy range $(2.2-2.5 \mathrm{eV})$ is increased by $150 \%$ with respect to that of $\mathrm{Au}_{16}{ }^{+}$(Figs. 3(a) and 3(b)). The appearance of absorption transitions for $\mathrm{Au}_{15} \mathrm{Pd}^{+}$in the low energy range may, as for $\mathrm{Au}_{12} \mathrm{Pd}^{+}$, be related to the dopant induced presence of low energetic unoccupied states. $\mathbf{A u}_{\mathbf{1 6}} \mathbf{P} \mathbf{P d}^{+}$shows four broad absorption bands with maxima at 2.48, 2.8, 3.12, and $3.4 \mathrm{eV}$, which are blue shifted with respect to features in the absorption spectrum of $\mathrm{Au}_{17}{ }^{+}$. The integrated absorption cross section of $\mathbf{A u}_{16} \mathbf{P d} d^{+}$does not decrease compared to $\mathrm{Au}_{17}{ }^{+}$in the low energy $1.9-2.5 \mathrm{eV}$ range, while it does decrease in the higher energy range.

The absorption cross sections of $\mathbf{A u}_{17} \mathbf{P d}^{+}$and $\mathbf{A u}_{18} \mathbf{P d}^{+}$in the low energy range (1.9-2.5 eV) are $110 \%$ and $100 \%$ higher than those of the respective pure $\mathrm{Au}_{18}{ }^{+}$and $\mathrm{Au}_{19}{ }^{+}$clusters. In the higher energy range, quenching of some absorption bands is observed upon Pd doping. In particular, the band between 2.6 and $2.9 \mathrm{eV}$ in the absorption spectrum of $\mathrm{Au}_{18}{ }^{+}$has disappeared and the major broad band between 2.9 and $3.4 \mathrm{eV}$ is replaced in the absorption spectrum of $\mathrm{Au}_{17} \mathrm{Pd}^{+}$by two smaller features centered near 3.0 and $3.4 \mathrm{eV}$. In the absorption spectrum of $\mathrm{Au}_{18} \mathrm{Pd}^{+}$, the band near $2.8 \mathrm{eV}$ is not much changed in comparison with $\mathrm{Au}_{19}{ }^{+}$, but the characteristic feature at $3.0 \mathrm{eV}$ observed for $\mathrm{Au}_{19}{ }^{+}$is not pronounced for $\mathrm{Au}_{18} \mathrm{Pd}^{+}$.

Bands in the absorption spectrum of $\mathbf{A u}_{19} \mathbf{P d}^{+}$are not much shifted in energy with respect to those of $\mathrm{Au}_{20}{ }^{+}$. In the low energy range $(1.9-2.5 \mathrm{eV})$, the intensity is not altered a lot, while in the higher energy range, their intensity is considerably reduced. The total absorption cross section has decreased by $33 \%$.

The overall decrease of the optical absorption upon Pd doping reflects dopant induced changes in the clusters' electronic structure. Recent XANES experiments for AuPd alloy nanoparticles showed that alloying increases the d-electron density at the Au sites. The more Au-Pd bonds the alloys have, the more the electron occupancies change. ${ }^{48,63}$ Such charge transfer from Pd to Au 5d orbitals agrees well with electronegativity values (Pauling's electronegativity of Au (2.54) is higher than the one of $\mathrm{Pd}(2.2)$ ) and with the relative positions of energy levels at $\mathrm{Au}$ and $\mathrm{Pd}$ sites. It is plausible to assume that the increase of the Au 5d-electron occupancy also occurs in small single Pd doped gold clusters.

Optical absorptions in the visible range mainly originate from $\mathrm{sp} \rightarrow \mathrm{sp}$ intraband transitions. As the $\mathrm{d}$ band of $\mathrm{Au}$ is situated close to its sp band, $d \rightarrow$ sp interband transitions are also important. ${ }^{60,64}$ For larger Au nanoparticles, an analogous decrease of the plasmonic absorption near $2.4 \mathrm{eV}$ upon Pd alloying was found in several studies. ${ }^{43-45}$ As a result of electron transfer from the Pd dopant to the Au 5d band, the energy separation between the Fermi level and the center of gravity of the $\mathrm{d}$ orbitals increases, which causes a reduction of the overlap between Au d and sp orbitals. Simultaneously, the unoccupied Au sp orbitals will hybridize with the empty Pd d states, which reduce the transition probability from occupied Au d states (Au $\mathrm{d} \rightarrow$ sp interband transitions). This can explain the Pd dopant induced decrease of the absorbance in the 1.9-3.4 eV range.

\section{SUMMARY AND CONCLUSIONS}

Pure and palladium doped cationic gold clusters, $\mathrm{Au}_{n}{ }^{+}$ and $\mathrm{Au}_{n-1} \mathrm{Pd}^{+}$, reveal a high likelihood for $\mathrm{Xe}$ attachment if $n \leq 19$ and $n \leq 20$, respectively, which decreases drastically 
for larger sizes. This could be exploited to perform action absorption spectroscopy experiments in the visible range. All investigated $\mathrm{Au}_{n}{ }^{+}$and $\mathrm{Au}_{n-1} \mathrm{Pd}^{+}(13 \leq n \leq 20)$ clusters show broad overlapping optical absorption bands in the high energy part of the spectrum (2.55-3.4 eV) and a few less intense bands at lower energies $(1.9-2.55 \mathrm{eV})$.

The total optical absorption cross section of the pure cationic gold clusters increases with cluster size, the cationic $\mathrm{Au}_{20}{ }^{+}$showing the highest value. The increase of the integrated absorption cross section with size is non-monotonic. Clusters consisting of 15, 17, and 20 atoms have a higher integrated optical absorption cross section than the neighboring sizes. An intense absorption band near $3 \mathrm{eV}$ was observed for $\mathrm{Au}_{n}{ }^{+}$ clusters composed of an odd number of atoms and for $\mathrm{Au}_{20}{ }^{+}$. $\mathrm{Au}_{15}{ }^{+}$reveals the highest absorption cross section among the investigated clusters in the energy range of $2.79-3.38 \mathrm{eV}$ being behind only the one of $\mathrm{Au}_{20}{ }^{+} . \mathrm{Au}_{13}{ }^{+}$is the only investigated cluster for which no optical transitions are observed in the energy range below $2.55 \mathrm{eV}$.

Replacing a single $\mathrm{Au}$ atom by a Pd atom in $\mathrm{Au}_{n}{ }^{+}(13 \leq n$ $\leq 20$ ) leads to dramatic changes of the optical excitation spectra. Doping results in a significant decrease of the integrated absorption cross section as well as in shifts of the transition energies. The influence of the dopant atom is most pronounced for $\mathrm{Au}_{n-1} \mathrm{Pd}^{+}$with $n=15-17$ and 20. While there is a pronounced decrease of the absorption cross section in the high energy range (2.79-3.38 eV) for all sizes, the absorption cross section increases for several sizes in the low energy range (1.9-2.49 eV), i.e., near the HOMO-LUMO gap. The appearance of low energetic transitions in the Pd doped clusters is particularly pronounced for $\mathrm{Au}_{17} \mathrm{Pd}^{+}$and $\mathrm{Au}_{18} \mathrm{Pd}^{+}$and is likely due to the presence of unoccupied electronic levels which are derived from empty Pd $4 d$ and 5 s orbitals. Similarly for the pure cationic gold clusters, an increase of the integrated absorption cross section with cluster size is found for $\mathrm{Au}_{n-1} \mathrm{Pd}^{+}$, with the highest values for $n=18,19$, and 20. The decrease of the absorbance of gold clusters upon palladium doping in the high energy range can be attributed to hybridization of the unoccupied Au sp orbitals with empty Pd d states, thereby reducing the transition probability from occupied Au d states (Au d $\rightarrow$ sp interband transitions).

We hope that the present results will inspire theoreticians to further investigate the effect of palladium doping on the optical properties of small gold clusters.

\section{ACKNOWLEDGMENTS}

This work is supported by the Research FoundationFlanders (FWO), by the KU Leuven Research Council (BOF and GOA program), and by the COST Action MP0903 "Nanoalloy."

${ }^{1}$ H. M. Chen, C. K. Chen, C. J. Chen, L. C. Cheng, P. C. Wu, B. H. Cheng, Y. Z. Ho, M. L. Tseng, Y. Y. Hsu, T. S. Chan, J. F. Lee, R. S. Liu, and D. P. Tsa, ACS Nano 6, 7362 (2012)

${ }^{2}$ S. S. Rayalu, D. Josec, M. V. Joshia, P. A. Mangrulkara, K. Shresthac, and K. Klabunde, Appl. Catal., B 684, 142-143 (2013).

${ }^{3}$ W. H. Hung, M. Aykol, D. Valley, W. Hou, and S. B. Cronin, Nano Lett. 10, 1314 (2010).

${ }^{4}$ T. Bernhardt, U. Heiz, and U. Landman, "Chemical and catalytic properties of size-selected free and supported clusters," in Nanocatalysis, Nanoscience and Technology (Springer, Berlin, Heidelberg, 2007).

${ }^{5}$ I. X. Green, W. Tang, M. Neurock, and J. T. Yates, Jr., Science 333, 736 (2011).

${ }^{6}$ H. A. Atwater and A. Polman, Nat. Mater. 9, 205 (2010).

${ }^{7}$ D. M. Schaadt, B. Feng, and E. T. Yu, Appl. Phys. Lett. 86, 063106 (2005).

${ }^{8}$ S. J. Chang, T. J. Hsueh, I. C. Chen, and B. R. Huang, Nanotechnology 19, 175502 (2008).

${ }^{9}$ A. Kolmakov, D. O. Klenov, Y. Lilach, S. Stemmer, and M. Moskovits, Nano Lett. 5, 667 (2005).

${ }^{10}$ K. Kneipp, Y. Wang, H. Kneipp, L. T. Perelman, and I. Itzkan, Phys. Rev. Lett. 78, 1667 (1997).

${ }^{11}$ Y. S. Chen, H. Choi, and P. V. Kamat, J. Am. Chem. Soc. 135, 8822 (2013).

${ }^{12}$ Y. A. Akimov, K. Ostrikov, and E. P. Li, Plasmonics 4, 107 (2009).

${ }^{13}$ K. Okamoto, I. Niki, A. Scherer, Y. Narukawa, T. Mukai, and Y. Kawakami, Appl. Phys. Lett. 87, 071102 (2005).

${ }^{14}$ C. F. Bohren and D. R. Huffman, Absorption and Scattering of Light by Small Particles (John Wiley \& Sons, New York, 1998).

${ }^{15} \mathrm{~S}$. Gilb, K. Jacobsen, D. Schooss, F. Furche, R. Ahlrichs, and M. M. Kappes, J. Chem. Phys. 121, 4619 (2004).

${ }^{16}$ B. A. Collings, K. Athanassenas, D. Lacombe, D. M. Rayner, and P. A. Hackett, J. Chem. Phys. 101, 3506 (1994).

${ }^{17}$ A. Schweizer, J. M. Weber, S. Gilb, H. Schneider, D. Schooss, and M. M. Kappes, J. Chem. Phys. 119, 3699 (2003).

${ }^{18}$ A. N. Gloess, H. Schneider, J. M. Weber, and M. M. Kappes, J. Chem. Phys. 128, 114312 (2008).

${ }^{19}$ S. M. Lang, P. Claes, N. T. Cuong, M. T. Nguyen, P. Lievens, and E. Janssens, J. Chem. Phys. 135, 224305 (2011).

${ }^{20}$ A. Shayeghi, R. L. Johnston, and R. Schäfer, Phys. Chem. Chem. Phys. 15, 19715 (2013).

${ }^{21}$ A. Terasaki, T. Majima, C. Kasai, and T. Kondow, Eur. Phys. J. D 52, 43 (2009).

${ }^{22}$ S. Lecoultre, A. Rydlo, C. Félix, J. Buttet, S. Gilb, and W. Harbich, J. Chem. Phys. 134, 074302 (2011).

${ }^{23}$ S. Bulusu, X. Li, L. S. Wang, and X. C. Zeng, J. Chem. Phys. C 111, 4190 (2007).

${ }^{24}$ P. Gruene, D. M. Rayner, B. Redlich, A. F. G. van der Meer, J. T. Lyon, G. Meijer, and A. Fielicke, Science 321, 674 (2008).

${ }^{25}$ A. Lechtken, C. Neiss, M. M. Kappes, and D. Schooss, Phys. Chem. Chem. Phys. 11, 4344 (2009).

${ }^{26}$ X. Xing, B. Yoon, U. Landman, and J. H. Parks, Phys. Rev. B 74, 165423 (2006).

${ }^{27}$ P. Pyykkö, Chem. Rev. 88, 563 (1988).

${ }^{28}$ S. Gilb, P. Weis, F. Furche, R. Ahlrichs, and M. M. Kappes, J. Chem. Phys. 116, 4094 (2002).

${ }^{29}$ W. Huang, S. Bulusu, R. Pal, X. C. Zeng, and L. S. Wang, ACS Nano 3, 1225 (2009).

${ }^{30}$ J. Li, H. J. Zhai, and L. S. Wang, Science 299, 864 (2003).

${ }^{31}$ E. S. Kryachko and F. Remacle, Int. J. Quantum Chem. 107, 2922 (2007).

${ }^{32}$ B. A. Wells and A. L. Chaffee, J. Chem. Phys. 129, 164712 (2008).

${ }^{33}$ C. Song, Q. Ge, and L. Wang, J. Phys. Chem. B 109, 22341 (2005).

${ }^{34}$ H. T. Le, S. M. Lang, J. De Haeck, P. Lievens, and E. Janssens, Phys. Chem. Chem. Phys. 14, 9350 (2012).

${ }^{35}$ J. Graciani, J. Oviedo, and J. F. Sanz, J. Phys. Chem. B 110, 11600 (2006).

${ }^{36}$ W. Bouwen, F. Vanhoutte, F. Despa, S. Bouckaert, S. Neukermans, L. T. Kuhn, H. Weidele, P. Lievens, and R. E. Silverans, Chem. Phys. Lett. 314, 227 (1999).

${ }^{37}$ M. Heinebrodt, N. Malinowski, F. Tast, W. Branz, I. M. L. Billas, and T. P. Martin, J. Chem. Phys. 110, 9915 (1999).

${ }^{38}$ S. Neukermans, E. Janssens, Z. F. Chen, R. E. Silverans, P. v. R. Schleyer, and P. Lievens, Phys. Rev. Lett. 92, 163401 (2004).

${ }^{39}$ N. Veldeman, E. Janssens, K. Hansen, J. De Haeck, R. E. Silverans, and P. Lievens, Faraday Discuss. 138, 147 (2008).

${ }^{40}$ B. Yoon, P. Koskinen, B. Huber, O. Kostko, B. von Issendorff, H. Häkkinen, M. Moseler, and U. Landman, ChemPhysChem 8, 157 (2007).

${ }^{41}$ X. L. Lozano, C. Mottet, and H. C. Weissker, J. Phys. Chem. C 117, 3062 (2013).

${ }^{42}$ G. Barcaro, M. Broyer, N. Durante, A. Fortunelli, and M. Stener, J. Phys. Chem. C 115, 24085 (2011).

${ }^{43}$ D. Jana, A. Dandapat, and G. De, J. Phys. Chem. C 113, 9101 (2009).

${ }^{44}$ B. Lim, H. Kobayashi, T. Yu, J. Wang, M. J. Kim, Z. Y. Li, M. Rycenga, and Y. Xia, J. Am. Chem. Soc. 132, 2506 (2010).

${ }^{45}$ J. W. Hu, Y. Zhang, J. F. Li, Z. Liu, B. Ren, S. G. Sun, Z. Q. Tian, and T. Lian, Chem. Phys. Lett. 408, 354 (2005). 
${ }^{46}$ A. Bruma, F. R. Negreiros, S. Xie, T. Tsukuda, R. L. Johnston, A. Fortunelli, and Z. Y. Li, Nanoscale 5, 9620 (2013).

${ }^{47}$ S. Link, Z. L. Wang, and M. A. El-Sayed, J. Phys. Chem. B 103, 3529 (1999).

${ }^{48}$ T. Balcha, J. R. Strobl, C. Fowler, P. Dash, and R. W. J. Scott, ACS Catal. 1, 425 (2011).

${ }^{49}$ S. Nishimura, A. T. N. Dao, D. Mott, K. Ebitani, and S. Maenosono, J. Phys. Chem. C 116, 4511 (2012).

${ }^{50}$ D. Cheng, H. Xu, and A. Fortunelli, J. Catal. 314, 47 (2014).

${ }^{51}$ D. W. Yuan, Y. Wang, and Z. Zeng, J. Chem. Phys. 122, 114310 (2005)

${ }^{52}$ J. De Haeck, N. Veldeman, P. Claes, E. Janssens, M. Andersson, and P. Lievens, J. Phys. Chem. A 115, 2103 (2011).

${ }^{53}$ K. Koyasu, M. Mitsui, A. Nakajima, and K. Kaya, Chem. Phys. Lett. 358, 224 (2002).

${ }^{54}$ W. Bouwen, P. Thoen, F. Vanhoutte, S. Bouckaert, F. Despa, H. Weidele, R. Silverans, and P. Lievens, Rev. Sci. Instrum. 71, 54 (2000).

${ }^{55}$ S. Öğüt, J. C. Idrobo, J. Jellinek, and J. Wang, J. Cluster Sci. 17, 609 (2006)
${ }^{56}$ W. Huang and L. S. Wang, Phys. Rev. Lett. 102, 153401 (2009).

${ }^{57}$ S. M. Lang, P. Claes, S. Neukermans, and E. Janssens, J. Am. Soc. Mass Spectrom. 22, 1508 (2011).

${ }^{58}$ See supplementary material at http://dx.doi.org/10.1063/1.4906072 for (i) the fraction of $\mathrm{Ar}$ complexes for $\mathrm{Au}_{n}{ }^{+}$and $\mathrm{Au}_{n-1} \mathrm{Pd}^{+}$, (ii) a comparison of the optical absorption spectra of $\mathrm{Au}_{14}{ }^{+} \cdot \mathrm{Xe}$ and $\mathrm{Au}_{14}{ }^{+} \cdot \mathrm{Xe}_{2}$, and (iii) a comparison of the experimental absorption spectra of the cationic $\mathrm{Au}_{13}{ }^{+} \cdot \mathrm{Xe}$ and $\mathrm{Au}_{20}{ }^{+} \cdot \mathrm{Xe}$ with calculated spectra for neutral $\mathrm{Au}_{13}$ and $\mathrm{Au}_{20}$.

${ }^{59}$ A. Lechtken, C. Neiss, J. Stairs, and D. Schooss, J. Chem. Phys. 129, 154304 (2008).

${ }^{60}$ J. C. Idrobo, W. Walkosz, S. F. Yip, S. Ögüt, J. Wang, and J. Jellinek, Phys. Rev. B 76, 205422 (2007)

${ }^{61}$ M. Walter and H. Häkkinen, Phys. Chem. Chem. Phys. 8, 5407 (2006).

${ }^{62}$ L. M. Wang, S. Bulusu, H. J. Zhai, X. C. Zeng, and L. S. Wang, Angew. Chem., Int. Ed. 46, 2915 (2007).

${ }^{63}$ F. Liu, D. Wechsler, and P. Zhang, Chem. Phys. Lett. 461, 254 (2008).

${ }^{64}$ C. M. Aikens and G. C. Schatz, J. Phys. Chem. A 110, 13317 (2006). 